\title{
The Conundrum in Accessing Business Development Services among Urban Informal Manufacturers in Dar es Salaam, Tanzania
}

\author{
Mubarack H. Kirumirah ${ }^{1}$, Emmanuel J. Munishi ${ }^{2}$ \& Anna E. Kajubili ${ }^{3}$ \\ ${ }^{1}$ Department of Business Adminstration, College of Business Education, P.O Box 1968 Dar es Salaam, Tanzania \\ ${ }^{2}$ Department of Business administration, College of Business Education, Tanzania \\ ${ }^{3}$ Postgraduate student, College of Business Education, Tanzania \\ Correspondence: Mubarack, H. Kirumirah, Department of Business Adminstration, College of Business \\ Education, P.O Box 1968 Dar es Salaam, Tanzania. E-mail: m.kirumirah@cbe.ac.tz/ babamuba@gmail.com
}

Received: October 17, 2021

doi:10.5539/ijbm.v16n12p119
Accepted: November 20, 2021 Online Published: November 30, 2021

URL: https://doi.org/10.5539/ijbm.v16n12p119

\begin{abstract}
This study examined the extent at which informal manufacturers' access Business Development Services (BDS). The study inquired about the extent of access and constraints to such access. The study was carried out in Dar es Salaam and mixed methods approach was used to study the phenomena. Using purposive and simple random sampling, researchers used a sample of 150 respondents from among manufactures and officials from different organizations. Data were collected by the use of questionnaire, interviews and documentary review. The descriptive statistics performed through SPSS were used in analysing quantitative data while content analysis run through MAXQDA10 was used to analyse qualitative data. Because the study was built on the contention that Business Development Services help in improving the performance of businesses, findings revealed that there is limited access to Business Development Services by urban informal manufactures in terms of training, financial assistance, legal related assistance and technical assistance among others which hinder their growth. The sluggish access to these services was caused by financial, information, technical, legislative, cultural and capacity related constraints. The study urged the government and its related organizations to value small start-ups by giving them all their necessary attention if they want the country to be more of an industrialized one. Business Development Services should be extended to these ventures bearing in mind that it is from these informal start-ups that disruptive industries emerge. Thus continuous trainings, financial and technical assistance should be given greater priority to urban informal manufacturers.
\end{abstract}

Keywords: urban informal manufacturers, business development services, access, Dar es Salaam

\section{Introduction}

The current proliferation of urban informal manufacturing has been widely promoted by massive campaigns of improving the industrial sector. Such campaigns, apart from economic growth, they are geared towards alleviating the rate of unemployment and abject poverty among urban dwellers (Mbelle \& Kabanda, 2018). As a result of such campaigns, Tanzania is mentioned among countries with a greatest segment of people employed in the informal sector in comparison to other countries in Africa (ILO, 2015; Mori, Kazungu \& Panga 2015; Dell'Anno, AnaMaria \& Balele, 2018; Munishi \& Casmir, 2019; Munishi \& Kirumirah, 2020a; Munishi \& Kirumirah, 2020b). Evidence further shows that, the informal sector has played and still plays major role of employment and earnings for rapidly growing populations adding that from 1985 to 2010 , the population bracket of 15-24 years of age doubled in the African and as a result urban informal trade almost tripled thanks to the less cumbersome regulations and taxation (Mgeni \& Nayak, 2015).

As a result of national wide campaigns of improving the industrialization sector, it has of recent been recorded that, the manufacturing sector in general accounts for around a quarter of Tanzania's gross domestic product (GDP) and its contribution to employment has grown over the past 10 years or so. The sector has had a number of different subsectors including food processing and beverages, textile, skins and skin products, furniture and paper products, chemicals and pharmaceuticals, rubber and plastic products (Mbelle \& Kabanda, 2018) and the sector has been growing vibrantly. However, with regards to the informal urban manufacturing, the sector is still described to be weak by considering the segment it contributes to the national income, exports and employment 
creation (Mbelle \& Kabanda, 2018). The sluggish development of the sector is partly attributed to inadequacy of Business Development Services (BDS) support.

To SMEs and the informal sector development, Business Development Services (BDS) support are of paramount importance. They provide important skills, information, principles and abilities that guarantee sales, profitability as well as business sustainability (Munishi \& Kirumirah, 2020; Munishi \& Casmir, 2019; Oosthuizen, 2008). BDSs refer to the provision of information, knowledge and skills, as well as advice on the various aspects of a business. They are also defined in terms of those non-financial services and products offered to entrepreneurs at various stages of their business needs (IFC, 2021). These involve a set of business- related information, knowledge, skills and advice that are provided to entrepreneurs with an intention of improving their operations (ILO, 2000), through which new ideas on increasing productivity, reducing production costs, or accessing a more profitable market (ILO, 2000) are obtained. It has thus been recorded that BDS are needed throughout the business idea generation, start up and expansion stages, with each stage requiring its specific BDS.

Due to its importance, BDS and the informal sector have attracted a number of scholars to study their existing relationship. While a study by Ombi, Ambad and Bujang (2018) revealed a positive relationship between BDS and SME performance, Mori (2015) had earlier reported a positive relationship between BDS and SME development. Furthermore, a study by Lwidiko, et al. (2019) reveals that BDS enhance SMEs to access finance from financial institutions in Tanzania. Another study related to this is that of Mori (2015). In this study, the rate at which the youth owned enterprises access BDS was studied and it was established that access to professional business advise and training have great impact in the development of youth owned enterprises. Such findings build a strand through which the importance of BDS support among the informal manufacturers can be observed.

Despite the critical significance attached to these services and the various efforts undertaken to ensure the provisions of these services to the subsector, still there is significant lack of access to BDS support by the urban informal manufacturers. More, specifically, traders in the Informal manufacturing are still confronted with, poor quality and inviable business ideas, inability to prepare business plans, inadequate knowledge and know how on product differentiation, or identify markets, business viability. While financial institutions that were expected to provide such services have not adequately done their duty(Mbura \& Merezia, 2015), the government and other NGOs have also not done enough to those involved in the subsector. Thus, with dearth in literature about the subject, little is known about how the urban informal manufacturers access BDS and what impedes them from accessing the same. Hence, this study entail to answer two basic questions; what is current status of access to Business Development services and support by the urban informal manufacturers? What are constraints to accessing Business Development services by the urban informal manufacturers in Dar es Salaam? The study will inform policy makers the extent to which informal manufacturers-who are envisaged to own big industries in future are constrained in accessing BDS support.

\section{Materials Studied}

\subsection{Access to BDS among the Informal Manufacturers}

A number of scholars have extended their efforts to investigate how different ventures have accessed BDS in their bid to achieve sustainable development. While these studies had contradicting and inconclusive findings, opens a room for more investigation into the matter. A study by Ackah and Vuvor (2011) highlighted on the issues facing SMEs in Ghana in their quest to access bank credit from the financial institutions and other BDS. It was revealed that SMEs could easily get access to BDS and financial assistance from financial institutions. Furthermore, Mwangemi, Wilson and Mugatu (2017) while presenting the Kenyan experience revealed that, access to BDS and financial assistance was fifty-fifty. While other SMEs received such assistance others had never received any of these. However, on the Tanzanian side, findings from different scholars reveal that (Mazania \& Fatoki, 2011; IMED, 2016; Yahya \& Muttarubukwa, 2018) SMEs had never received any of BDS support despite their importance in employment creation, poverty alleviation and sustainable development. This was attributed to the informal status ascribed to them, limited entrepreneurial education, poor networking and limited government support in improving the performance of SMEs. The prevalence of such contradictory findings, and treating SMEs as a general term creates a room for more investigation in the matter and specifically with urban informal manufacturers.

\subsection{Constraints in Accessing BDS to Informal Manufacturers}

Bearing in mind that SMEs have been reported to have limited access to BDS support, there must be social, economic and politically oriented challenges constraining SMEs. Different scholars have taken interest in the phenomena, and have identified several constrains. A study by Baporikr, Nambira and Gomxos (2016) identified limited network, security problem and fights from the customers as well as low pace to capture the changing 
technology. Willian (2017) revealed lack of organization and failure of being registered in groups. Bakhtiari et al. (2020) identified volatility of the market and inadequacy of registered resources. As for Chittithaworn et al. (2011) the nature of customers, market, SMEs characteristics, resources, method of doing business, finance and external challenges constrain SMEs from accessing BDS support. In the Tanzania context, constrains related to trust and poor government support and tight regulations (Nkwabi \& Mboya, 2019), inadequate business training, anti- entrepreneurial culture (Mashenene \& Rumanyika, 2014), high interest rates, costs of obtaining such services (Ackah \& Vuvor, 2011) as well as limited entrepreneurial skills, high tax rates, and government cumbersome policies (Souza et al., 2013) were recorded to be among constrains that hinder SMEs to access BDS support. Despite the presence of these studies, these studies were generic in nature and none of them focused on urban informal manufacturers which the extant study intends to do.

\subsection{Theoretical Underpinning of the Study}

The study is hinged on two theories i.e. the innovation theory and creation theory. While the innovation theory considers an entrepreneur as an innovator with different skills (Acs \& Audretsch, 1988) and covers areas of introduction of new goods which the consumer is not familiar with, introduction of new production method that are not yet tested, the opening of the new market, capture of new source of supply of raw materials or half manufactured goods and the carrying out of new organization of any industry; the creation theory with its main assumptions considers opportunities to be subjective, created through a series of decisions, opportunity do not have existence without the actions of entrepreneurs and they can be discovered by scanning business environment and analysing the market and industry structure. The study finds both theories useful in the sense that entrepreneurs are innovators and make use of the available opportunities in the urban settings, thus, BDS support would help them to become more productive and progressive to become fully furnished manufacturing industries. Both theories in this study were used as a lens in data collection as well as discussing findings obtained in this study.

\section{Area Descriptions}

The study was carried out in Dar es Salaam, a major commercial hub in Tanzania and business centre for largest number of enterprises including small and medium businesses. It is also, the centre for all major economic activities, hence easy to access information from targeted population (Possi \& Milinga, 2018). Dar es Salaam has five municipals which are Ilala, Temeke, Kinondoni, Kigamboni and Ubungo (DCC, 2017). Being a major business hub in Tanzania, it has attracted the migration of different individuals who are entirely searching for economic opportunities (Kirumirah \& Munishi, 2021), some of whom have become urban informal manufacturers. The study covered the three municipals of Ilala, Temeke and Kinondoni as the major selected area with many informal manufacturing entities as per Small Industries Development Organizations (SIDO).

\section{Methods and Techniques}

\subsection{Research Approach and Design}

The study employed a mixed methods research approach in which both qualitative and quantitative data were collected concurrently, analysed and their meaningful interpretations generated. The researcher employed this technique to capture both qualitative and quantitative aspects in order to complement on the weaknesses of each specific method (Creswell et al., 2011). Due to the nature of the study as it sought to explain the phenomena, generating knowledge, develop new understanding on the subject matter of the study, the explanatory design was more relevant than other designs (Adam \& Kamuzora, 2008).

\subsection{Sampling and Sampling Techniques}

Researchers targeted different subsectors of urban informal manufacturing entities notably textile (tie and dye), furniture, food and beverages, soap and chemicals. Furthermore, staff from organizations dealing with business development for SMEs in Dar es Salaam were targeted to provide additional information and were used as key informants. Such organizations include; Small Industry Development Organization (SIDO), Tanzania Investment Centre (TIC), and Tanzania Trade Development Authority (Tan Trade), Tanzania private sector foundation (TPSF), Ministry of industries Trade, Financial Institutions (FIs) and Local Governments (LGs). From all these, a sample of 110 respondents were obtained. As a means of triangulating data, key informants were used in this study. These included 5 staff from SIDO, TIC, MIT, TPSAF, LGs and Tan Trade; as well as 10 loan officers from commercial banks. The study obtained this sample based on the rule of thumb where the sample size for a study should at least be $\mathrm{N} \geq 103+\mathrm{M}$, where $\mathrm{N}=$ sample size, $\mathrm{M}=$ number of independent variables namely Access to BDs and Constraints (Green, 1991). Furthermore, because large sample sizes provide reliable data that can be a representative of the entire population, thus 110 was regarded more appropriate. While respondents were 
obtained by convenient sampling, key informants were chosen purposively based on their knowledge, experience and positions they held with regards to the topic under the study.

\subsection{Data Collection Techniques}

The study collected data by using questionnaire, interview and documentary review. While questionnaires were self-nature administered to urban informal manufacturers and included five points Likert scale questions, interviews were carried to selected staff from different organizations. A set of interview guide was used to direct the nature of the interview. For interviews, each interview lasted for up to 45 minutes and was recorded. Researchers ensured that all interviewees were asked the same questions, unless more probing was prompted.

\subsection{Data Analysis}

Collected data were in two forms, that is qualitative and quantitative ones. Each set of data was treated separately. To both datasets, cleaning and reducing and coding were done. Data with quantitative nature were subjected to SPSS and descriptive statistics were used to make meaning out of the analysed data. As for qualitative data, MAXQDA 10 was used to code and make meaningful expressions. In this regard, descriptive statistics obtained were explained and cemented by quotes obtained from interviews and documentary reviews. Throughout the study, all ethical standards were adhered.

\section{Findings and Discussions}

\subsection{Respondents' Demographic Information}

The demographic information of the respondents includes age, sex, gender, education as well as the capacity or rather the office position. Accordingly, respondents with an age bracket of $18-28$ years represented $15.3 \%$, those aged between $29-38$ years were $32.2 \%$, those aged between $39-48$ years were $26.3 \%$; $49-59$ years were $18.6 \%$; and lastly respondents aged between 59 years and above were $7.6 \%$ of all respondents. Thus it was revealed that majority of respondents were mature and were capable of providing relevant responses to questions asked by the researcher.

With regards to gender, findings revealed interesting findings in the sense that in comparison to previous years, the number of women involved in economic activities has increased rapidly. In total, there are $41.3 \%$ of female manufacturers as opposed $58.6 \%$ of male manufacturers in the urban settings. In addition, respondents were categorized basing on their level of education noting that there were $17.5 \%$ of respondents holding Master's degree, $25.3 \%$ with a Bachelor's degree, $13.6 \%$ Diploma holders and $33.3 \%$ holding secondary level of education.

\subsection{Access to Business Development Services Support by the Urban Informal Manufacturers in Dar es Salaam}

This formed the first question that the study envisaged to answer. It was aimed at revealing to what extent urban informal manufacturers access DBS support. Aspects examined included access of services from lending institutions, access to marketing services, existence of relevant polices, access to training, technical assistance, youth influence for access for BDS, access to internet and social media in relation to their businesses.

Table 1. Descriptive results on access to business development services and support by the urban informal manufacturers in Dar es Salaam

\begin{tabular}{ll}
\hline Aspects & Mean Score \\
\hline Access to business capital from development and financial institutions & 2.84 \\
Access to testing of goods and services quality standards & 2.80 \\
Access to special business premises/spaces. & 2.76 \\
Access to regular and relevant training & 2.51 \\
Access to technical assistances to establish and expand business & 2.25 \\
Access to machines, equipment loans & 1.97 \\
Legal advice from stakeholders wherever is needed & 2.12 \\
Access reliable source of information & 2.34 \\
\hline
\end{tabular}

Bearing in mind that questionnaire contained a five points Likert scale questions, researchers decided to use the mean score as the measure for access to BDS support. Researchers ranked scores 5.0-4.0 as adequate access, 3.0-2.5 as average access and 2.4-1.0 as poor and unsatisfactory access to BDS. Findings as presented in Table 1 indicate that access to business capital from development and financial institutions had a mean score of 2.84 
implying that urban informal manufacturers have average access to BDS support in Tanzania. Such findings are cemented by interview responses from selected financial institutions which contended that financial institutions fail to provide loans to urban informal manufacturers because they cannot be trusted to repay debts out of their small business while others fail to meet loan requirements which includes collaterals for securing loans. Another reason for failure to access loans from development sector was limited fund where one of the key respondents from the relevant government ministry and department articulated that:

"Dar es Salaam city council provides loans to informal small business targeting mostly on youth and women aged 18 years to 30 years. The loan is provided out of $10 \%$ of the earnings of the Council, where they offer loan amounting to Tanzanian Shillings Three Million (TZS. 3,000,000/-) to a group of 10 people where each businessman gets only Tanzanian Shillings Three Hundred Thousands (TZS. 300,000/-). This amount is very low and all this is due to limited fund of the municipals." (Female Local Government officer (50), Dar es Salaam).

With regards to access to testing of goods and service quality standards, results indicate that the aspect obtained a mean score of 2.8 indicating an average access to such services. This implies that Tanzania Bureau of Standards and Tanzania Drugs Authority do not provide full access of their services to informal urban manufactures. This was further recorded in the interview when one of the respondent was quoted saying;

Majority of informal manufacturers do not access foreign markets because their products are below internationally accepted standards especially foods and beverages. Tanzania Bureau of Standard (TBS) has not been accredited internationally and as a result informal manufacturers fail to access international markets. Besides formal businessmen are required to go to other countries for standardization like Kenya and South Africa which is also difficult to afford. (Male, government official (46), Dar es Salaam).

Such findings, reveal a cumbersome nature of accessing labs for testing the quality of goods and services. The situation further reveals that even those that require to obtain TBs certificate have to go through a very long process making the exercise completely inaccessible to many manufacturers.

Access to business premises and spaces was also measured and obtained mean score of 2.76. This is indicative that not all urban manufacturers have premises. It represents an average status on the aspect. In the open ended questions in the questionnaire, some of them recorded that they cannot afford to rent good premises for doing business due to high leasing rate, tax implications and limited allocated premises for doing business from the government as a results it becomes difficult to access support from development sectors without having specific business location.

On access to regular training and seminars for urban informal manufacturers, findings as depicted in Table 1 reveal that the extent at which manufacturers receive training and seminars is at an average rate with a mean score of 2.51. This implies that majority of respondents contend that there are inadequate trainings and seminar for urban manufacturers from different stakeholders. In the interview it was found that absence of enough training limits the understanding on the best ways of developing business. There is no specific system of providing training to urban informal manufacturers. This was further articulated by the respondents that:

"Dar es Salaam City Council provides training to small informal manufacturers particularly on how to find markets, better location of doing business. It also finances exhibitions where informal businessmen can acquire skills. However, there is a limited number of small businessmen and limited fund to reach all informal manufacturers." (Female local Government officer (43) May, Dar es Salaam).

This cements the truth that even though trainings are provided, informal urban manufacturers have an average access to them.

With regards to access to manufacturing related assistance, findings obtained indicate that, the aspect score a mean score of 2.25 which is below the average and indicates poor access to such service and support. Even though there are a number of organizations that would provide such assistance but unfortunately such assistance is obtained on a low extent. In the interview with Tanzania Private Sector Foundation it was found that:

"Tanzania Private Sectors Foundations offers capacity building to upgrade informal manufacturers to become SME's this includes finding markets, favourable policy, skills and creating a link between informal manufacturers with financial institutions, however we have not provided this service to all" (Female, Tanzania Private Sectors Foundation (44) May, Dar es Salaam).

This is to say even though trainings are provided, urban informal manufacturers access them at a very low extent. This in one way or the other hinders their pace of growth and sustainability in general.

On the aspect of access to machine equipment and loans, findings as depicted in Table 1 reveal that the aspect 
has a mean score of 1.97 indicating limited access to such services to urban informal manufacturers. Such findings are cemented by those obtained during an interview with a LG officer who was quoted saying:

"At Temeke, Kinondoni and Ilala Municipal Council informal manufacturers are supported mostly in Kind where they are offered raw materials depending on the nature of their business. However, they reach very limited number of informal manufacturer due to limited fund" (Female Local Government Official (42), Dar es Salaam).

Findings imply that despite the reality that some support is provided but it has not been distributed to all manufacturers making the extent to which such service is obtained to be very low. There are very few who, though municipals, have obtained machines and equipment. This makes them steak to their rudimental means of manufacturing, hindering the quality of what they produce and development.

The extent to which informal manufacturers receive legal advice from different stakeholders was among the aspects that had very minimal scores (with a mean score of 2.12) indicating low and limited access. Further findings from the interview articulated that "Tanzania Private Sector Foundation provides trainings and education on capacity building including an advice on legal compliances including favourable policies and laws, however, we alone cannot cover all manufacturers in Dar es Salaam. So a lot are left unattended. Such findings are an indication that due to limited access to legal advice, some manufacturers may fall victims of rupturing regulatory requirements.

Findings with regards to access to reliable information reveal that, although urban informal manufacturers receive different information regarding their operations, the extent is low as depicted by findings in Table 1 with a men score of 2.34. It indicated that it is not everybody in the subsector that can access this information related to new services, markets and technology just to mention a few. In the interview with TCCIA it was revealed that, "TCCIA provides information depending on the available external markets where the informal manufacturers can trade, however there is a limited number of informal manufacturer whose produces meet international standards. Due to such hurdles some manufacturers have even been discouraged at seeking such information as they consider it less useful.

\subsubsection{Discussion}

The research findings revealed that majority of urban informal manufacturers do not get access to BDS support. This was proved through existence of limited access to lending capital. The responses reveal that the development sectors and banks offer limited lending capital to urban informal manufacturer which influence their limited growth. Findings are similar to those of Ackah and Vuvor (2011) who came out with similar observations that the small enterprises were not able to meet the collateral requirements to obtain capital loans and those who were able to access the credit were constrained with high interest rate and short repayment period which was difficult in achieving their goals.

The findings revealed also that there is low level of standards testing services of goods from the stakeholders like TBS as well as lack of special premises located for doing business. This reflects the findings by Lema (2013) who contended that informal sectors lacks permanent business places. This being the case, it becomes difficult to obtain continuous support without permanent locations of dosing business for supporters to access them. Another limitation found includes lack of access to the training and seminars; low technical assistances; limited loans for machine and equipment from stakeholders; lack of legal advice from stakeholders; and lack of reliable source of information. In similar research conducted by Yahya and Mutarubukwa (2015) it was revealed that the small enterprises could not access the business development services because they are incapable in taking the business opportunities due to low capital, lack of entrepreneurial education, networking activities which were social rather than business focused, as a results it affects the development of small businesses. General findings with regards to descriptive statistics are presented in the subsequent section.

\subsection{Constraints to Assessing Business Development Services by the Urban Informal Manufacturers in Dar es Salaam}

This was the second question that the research wanted to answer. In this part, constraints to accessing BDS among urban informal manufacturers in Dar es Salaam were revealed. Aspects examined includes financial constraints to compete with international entrepreneurs; supplying goods and services with a quality as required by the market; anti- entrepreneurial culture among informal manufacturers; inappropriate market information; high interests rates and collateral requirement; tax rate confusion and tax collection procedures; poor promotion of innovation and creativity; and financial barriers for survival of the business, and lack of trust to stakeholders. 
Table 2. Descriptive findings on constraints facing urban informal manufacturers to access business development services and support

\begin{tabular}{lc}
\hline Aspects & Mean Score \\
\hline Financial strength to compete with the international entrepreneur. & 3.45 \\
Financial strength in supplying of goods and service with standard quality as required by the market. & 3.32 \\
Anti-entrepreneurial culture among informal urban manufacturers hinders their motives. & 3.62 \\
Inappropriate marketing information & 3.65 \\
The interest rate and collateral requirement by banks and government development sectors. & 3.90 \\
Tax rate confusions and tax collection procedures. & 3.67 \\
Poor promotion of innovation and creativity. & 4.12 \\
Financial constraints for survival of an informal manufacturers business. & 3.52 \\
\hline
\end{tabular}

\subsubsection{Financial Constraints to Compete with International Entrepreneurs}

This was the first aspect examined under this objective and cited as one of the constraints. Following the same ranking as used in the first objective, the mean scores were ranked 5.0-3.1 as serious constraint, 3.0-2.5 as a constraint and 2.4-1.0 as minimal constraints. Findings as indicated in Table 2 reveal that financial constrain to compete with international entrepreneurs scored 3.45 and was regarded among serious constraints. This revealed that majority of urban informal manufacturers fails to compete with international entrepreneurs due to lack of enough capital. This was further elaborated by one of the key respondent that:

"Although TCCIA opens a room for informal manufacturers to trade in external market, but majority of manufacturers have very low capital to produce enough required products in terms of quantity and quality to be sold in external market as compared to other international entrepreneurs." (Male, Tanzania Chamber of Commerce, Industry and Agriculture (35) May, Dar es Salaam).

\subsubsection{Financial Barrier to Supply Goods and Services with Quality as Required by the Market}

This was the second aspect examined and considered a constraint to urban informal manufacturers in accessing BDS support. Findings reveal that, this was another serious constraints and scored a mean score of 3.32. This reveals that urban informal manufacturers produce goods with low qualities due to their limited capital hence fail to meet market requirements. Through interviews it was revealed that urban informal manufacturer fail to afford raw materials with good qualities for producing good products. It was also found that there is no standard processing machines for producing goods with standard qualities like machines for production and packaging of soap, foods and beverages.

\subsubsection{Anti-Entrepreneurial Culture among Informal Urban Manufacturers}

This was also examined as a constraint to urban manufacturers in accessing DBS support. Findings reveal that the aspect scored a mean score of 3.62 indicating it as a serious constraint. The interview reveals that although some governmental and non-governmental sectors put some initiatives to support business development but some informal urban manufacturers have anti-entrepreneurial culture hence not willing to take risks for development activities like taking loans. In the interview with Local Government Official it was stated that:

"Although Temeke, Kinondoni and Ilala Municipal Council offers loans to informal business manufacturers, by requiring them to form groups and prepare their business proposal but very few informal manufacturers are willing to take loans compared to number of existing informal manufactures" (Female Local Government official (42), Dar es Salaam).

Findings imply that very few urban informal manufacturers have little entrepreneurial culture and are unwilling to participate in a number of activities that would enhance their development.

\subsubsection{Inappropriate Market Information}

This was also a serious constraint to urban informal manufacturers with a mean score of 3.62. The existence of inappropriate market information hampers urban informal manufacturers to access DBS support. During an interview, the respondents contended that they are forced to offer their products for sell in the streets especially in the cities looking for customers who are not reliable. That they are not linked with their customers.

5.3.5 Interest Rate and Collateral Requirements by the Banks and Government Development Sectors

Interest rates and collateral requirements by financial institutions was among serious constraints of urban informal manufacturers' access to BDS support. Financial institutions require a lot of collateral securities and 
interest rates restrict manufacturers from accessing BDS. The aspect had a mean score of 3.90 implying that it is one of serious constraints to access to BDS support by informal manufacturers. This was supported by an interview which revealed that majority of urban informal manufacturers fail to access BDS because of the existing high interest rates when they take loans and the requirement of collateral to obtain loans which is a challenge because majority of informal manufacturers are poor and have no collaterals to secure loans.

\subsubsection{Tax Rate Confusions and Tax Collection Procedures}

This was another aspect that was considered a serious constraint to access to BDS by urban informal manufacturers. The aspect scored a mean of 3.67 which falls under serious constraints. It is evident that instead of providing tax advice, Tanzania Revenue Authority (TRA) only come to collect tax using unfriendly procedures. Majority of urban informal manufacturers fear to grow to formal business because they are not willing to pay tax which is very high and detrimental for their business development.

\subsubsection{Poor Promotion of Innovation and Creativity}

This was among the most serious constraints to accessing BDS support by urban informal manufacturers. It was revealed that despite the presence of different organizations incubating innovations, they have not honoured all innovations hence hindering urban informal manufacturers with new ideas as proposed by the innovation theory to be promoted through the use of BDS support. The picture painted by the findings as shown in Table 2 indicate that the aspect has a mean score of 4.12 which falls under being serious constraints.

\subsubsection{Financial Barriers for Business Survival}

Financial barriers were also assessed to determine if it affects the survival of the business of urban informal manufacturers. It was found that $12.6 \%$ strongly disagree, $10.7 \%$ disagree, $19.4 \%$ neither disagree nor agree, while $26.2 \%$ agree and the remained $31.1 \%$ strongly agree. In the interview, This is cemented by interview responses from selected financial institutions which contended that financial institutions fails to provide loans to urban informal manufacturers because they cannot be trusted to repay debts out of their small business while others fails to meet loan requirements which includes having a collateral for securing loans.

\subsubsection{Discussion}

The findings of this study revealed that failure of urban informal manufacturers to access business development services and support is caused by various constraints which includes lack of enough financial strength for informal urban manufacturers to compete with the international entrepreneur; poor quality of goods and services to meet market requirements; anti- entrepreneurial culture among urban informal manufacturers which hinders the motives to access the business development services; inappropriate market information; interest rate and collateral requirements by the bank and government development sectors; tax rate confusion and tax collection procedures; poor promotion of innovation and creativity; lack of finance for survival of business; and lack of trust from the stakeholders to financial constraints of urban manufacturers.

Findings in this objective concur with observations in the study by Nkwabi and Mboya (2019) who revealed that the Tanzania small informal sectors are impacted by financial constraints, capital contraints, poor technology and tight regulations which affects their business development. Other contraints were stated by Mashenene and Rumanyika (2014) which includes inadequate business training, insufficient capital and anti-entrepreneurial culture and limited trust as well as collateral security which are significant constraints that affects the potential growth of urban informal small manufacturers. Moreover, in the study by Yahya and Mutarubukwa (2015) it was reveled that Tanzanian Small enterprises could not easily acess the BDS due to low capital, lack of entrepreneurial education, networking activities which were social rather than business focused.

Findings further on this objective indicate that prior studies by different scholars that urban informal manufacturers are constrained by the nature of external support, limited access to market related information, limited financial assistance among others (Chittithaworn et al., 2011; Ackah and Vuvor, 2011). According to Williams (2017) across 41 African countries unregistered start-up firms suffers from poor performance compared start-up registered firms. This is due to limited capital and market pressure resulting to low commodity prices. They encounter challenges including lack of entrepreneurial skills and culture, lack of permanent centres for doing business, absence of market, too high taxes established and unstable weather conditions (Lema, 2013). Thus, this study has revealed clearly that the identified challenges in the past studies are still persisting as it is found under this study. Hence, findings imply that, amid government efforts of promoting industrialization, a lot has not been done to provide financial and technical support to enhance development of urban informal manufacturing. 


\section{Conclusion}

Findings indicate that there is inadequate access to BDS support among urban informal manufactures and all this is caused by various constraints which includes financial constraints to compete with international entrepreneurs, low quality of goods to meet market requirements, anti- entrepreneurial culture, inappropriate market information, high interests rates and collateral requirement, tax rate confusion and tax collection procedures, poor promotion of innovation and creativity, and financial barriers for survival of the business, and lack of trust to stakeholders. Based on findings obtained in this study, it can be concluded that even though the government is struggling hard to promote the industrial sector, this will not be realized if informal manufacturers are not helped to grow into becoming super industrial manufacturers. Based on these findings, the study recommends the following;

i. All government and non-government organizations should make sure that instead of suppressing new innovations, they should support them in all possible means so that they grow up into full-fledged manufacturing industries. Such support should be in form of training, access to capital, guarantee, and incubation among others. Organizations like SIDE, TIC, TanTrade, TPSF, MIT and others should assume these functions.

ii. The government and other related organizations should ensure that they extend adequate financial assistance to urban informal manufacturers. This can be done through increasing the budget of funds extended to them. Municipal and District councils across the country should increase the budget for empowering informal groups of women and the youth.by increasing the budget, a large number of them will access such financial assistance.

iii. Enough education is also recommended which includes provision of seminars, public lecturers, use of Medias to reach urban informal manufacturers for the purpose of increasing entrepreneurial skills, legal understanding and training on production of goods with quality as required by local and international market. This should be provided by all stakeholders including Small Industry Development Organization (SIDO), Tanzania Investment Centre (TIC), and Tanzania Trade Development Authority (Tan Trade), Tanzania private sector foundation (TPSF), Ministry of industries Trade and investment Financial Institutions sand local governments.

iv. Appropriate market and legal information should also be shared to urban informal manufacturers. For instance, the Tanzania Chamber of Commerce, Industry and Agriculture should find markets for the goods and services provided by urban informal manufacturers and share it to urban informal manufacturers. Moreover, different legal organizations should ensure that informal manufacturers should be provided with legal advice lest they enter in conflicts with the law.

v. The government through local government authorities are recommended to allocate specific premises for urban informal manufacturers to do their business. There should also be adequate facilities and instruments for better conducts of business which includes raw materials and access to other social services like water utilities and electricity.

vi. Enough information and legal services should be provided to urban informal manufacturers to ensure they are availed with information, policies and laws which protects their interests when conducting their business.

\section{Acknowledgement}

I wish to acknowledge the support given to researcher by heads and staff of the SIDO, Tanzania Chamber of Commerce, Industry and Agriculture, Tanzania Private Sector Foundation, all Commercial banks in Dar es salaam, Ilala, Kinondoni and Temeke Municipal Councils, Tanzania Investment Centre and Ministry of Industry and Trade.

\section{References}

Ackah, J., \& Vuvor, S. (2011). The Challenges faced by Small \& Medium Enterprises (SMEs) in Obtaining Credit in Ghana. Ghana: Blekinge Tekniska Hogskola School of Management.

Acs, Z., \& Audretsch, D. (1988). Innovation in Large and Small Firms: an Emperical analysis. American Economic Review, 78, 678-690. https://www.jstor.org/stable/1811167

Adam, J., \& Kamuzora, F. (2008). Research methods for business and social studies. Mzumbe book project, Mzumbe.

Bakhtiari, S., Breunig, R., Magnani, L., \& Zhang, J. (2020). Financial constraints and small and medium enterprises: A review. Economic Record, 96(315), 506-523. https://doi.org/10.1111/1475-4932.12560

Baporikar, N., Nambira, G., \& Gomxos, G. (2016). Exploring factors hindering SMEs' growth: Evidence from Namibia. Journal of Science and Technology Policy Management, 7(2), 190-211. 
https://doi.org/10.1108/JSTPM-11-2015-0036

Chittithaworn, C., Muhd Yusuf, D., \& Islam, A. (2011). Factors Affecting Business Success of Small and Medium Enterprises (SMEs) in Thailand. Asian Journal of Social Science, 7(5), 180-190. https://doi.org/10.5539/ass.v7n5p180

Creswell, J. W., Klassen, A. C., Plano Clark, V. L., \& Smith, K. C. (2011). Best practices for mixed methods research in the health sciences. Bethesda (Maryland): National Institutes of Health, 541-545.

Dell'Anno, R., AnaMaria, A., \& Balele, N. (2018). Estimating shadow economy in Tanzania: An analysis with the MIMIC approach. Journal of Economic Studies, 45(1), 100-113. https://doi.org/10.1108/JES-11-2016-0240

ILO. (2015). The Transition from the informal to the formal economy. Geneva: International labour organization.

IMED. (2016). A study on the Informal Sector with a View to Fornalization. Tanzania: Institute of Management and Entrepreneurship Development (IMED).

International Finance Corporation (2017). Small Business, Big Growth: How investing in SMEs creates jobs. International Finance Corporation. Washington. USA.

Kazungu, I., \& Panga, F. (2015). Empowering small and medium enterprises (SMEs) to harness public procurement opportunities. International Journal of Economics, Commerce and Management, 3(3), $112-131$

Lwidiko, B., Ishengoma, E., \& Baisi, M. D. (2019). The influence of Business Development Services (BDS) on access to finance of SMEs in Tanzania. Journal of African Business.

Makhitha, K. M. (2019). Marketing strategies for closing the market access gap experienced by small craft producers in South Africa. Journal of Business and Retail Management Research, 13(3).

Mashenene, R., \& Rumanyika, J. (2014). Business Constraints and Potential Growth of Small and Medium Enterprises in Tanzania: A Review. European Journal of Business and Management, 6(3), 72-79. http://hdl.handle.net/20.500.12018/165

Mazanai, M., \& Fatoki, O. (2011). The effectiveness of Business Development Services providers (BDS) in improving access to debt finance by start-up SMEs in South Africa. International Journal of Economics and Finance, 3(4), 208-216. https://doi.org/10.5539/ijef.v3n4p208

Mbelle, A., \& Kabanda, H. (2018). Recent Progress Towards industrialization in Tanzania. Economic and Social Research Foundation (ESRF). from https://set.odi.org/recent-progress-towards-industrialisation-in-tanzania-briefing-paper/

Mbura, O., \& Merezia, W. B. (2015). Success and usefulness of business development services in Tanzania's SMEs market. Business Management Review, 18(2), 1-19. http://hdl.handle.net/20.500.11810/4697

Mgeni, T. O., \& Nayak, P. (2015). Impact of different leadership styles of CEOs on business performance of SMEs in East Africa: A systematic review of literature. Journal of Entrepreneurship \& Management, 4(3), 1-13. Retrieved from http://www.publishingindia.com

Mori, N. (2015). Access to Business Development Support Services and Performance of Youth-Owned Enterprises in Tanzania. Journal of Entrepreneurship Management and Innovation (JEMI), 11(2), 57-82. Retrieved from https://www.ceeol.com/search/article-detail?id=309066

Munishi, E. J., \& Kirumirah, M. (2020). Skills gap among the Urban Street vendors in Tanzania: Cases of Dar es Salaam and Morogoro Urban settings. Business Education Journal (BEJ) 2(1). Retrieved from https://bej.cbe.ac.tz/index.php/bej/article/view/218

Munishi, E., \& Casmir, R. (2019). Overcoming Business Capital Inadequacy and Resilience Implications for the Urban Street Vendors' Operations in Morogoro Municipality. Business Education Journal (BEJ), 1(1), 1-18. Retrieved from http://dspace.cbe.ac.tz:8080/xmlui/handle/123456789/145

Munishi, E., \& Kirumirah, M. (2020). Vendors' Licensing and Permit Issuing in Urban Setting: Constraints and Implications for Vending Operations in Dar es Salaam - Tanzania. Business Education Journal (BEJ), 4(1), 34. Retrieved from http://dspace.cbe.ac.tz:8080/xmlui/handle/123456789/520

Mwangemi, J., Wilson, C., \& Mungatu, J. (2017). The Influence of Access to Finance and Government Policies on the Growth of Small and Micro-Enterprises Growth in Kenya. Kenya: Jomo Kenyatta University of Agriculture and Technology. 
Nkwabi, J., \& Mboya, L. (2019). A review of factors affecting the growth of small and medium enterprises (SMEs) in Tanzania. European Journal of Business and Management, 11(33), 1-8. https://doi.org/10.7176/EJBM/11-33-01

Ombi, N., Ambad, S. N. A., \& Bujang, I. (2018). The effect of business development services on small medium enterprises (SMEs) performance. International Journal of Academic Research in Business and Social Sciences, 8(3), 117-130. https://doi.org/10.6007/IJARBSS/v8-i3/3910

Oosthuizen, C. (2008). Skills Needed to Move From the Street Vendor to Shop Owner. United States: Potchefstroom Campus of North-West University.

Possi, M. K., \& Milinga, J. R. (2018). Perceptions on people with albinism in urban Tanzania: implications for social inclusion. Journal of Advocacy, Research and Education, (5), 81-92. Retrieved from http://kadint.net/our-journal.html

Souza, G. D., Costa, A. C. S., Lima, N. C., Coelho, J. D. M., Penedo, A. S. T., \& Silva, T. E. E. (2013). Structures of commercialization: actions of informal marketing from Brazilian micro-entrepreneurs in a street market. International Journal of Business and Commerce, 2(9), 20-36.

Yahya, M., \& Mutarubukwa, P. (2015). Capacity of Tanzania micro, small and medium enterprises in tapping the business opportunities in the East African Community. Business Education Journal 1(1), 1-20. Retrieved from http://www.cbe.ac.tz/bej

\section{Copyrights}

Copyright for this article is retained by the author(s), with first publication rights granted to the journal.

This is an open-access article distributed under the terms and conditions of the Creative Commons Attribution license (http://creativecommons.org/licenses/by/4.0/). 